\title{
Modulation of rat hepatic and kidney phase II enzymes by cabbage juices: comparison with the effects of indole-3-carbinol and phenethyl isothiocyanate
}

\author{
Violetta Krajka-Kuźniak ${ }^{1}$, Hanna Szaefer ${ }^{1}$, Agnieszka Bartoszek ${ }^{2}$ and Wanda Baer-Dubowska ${ }^{1 *}$ \\ ${ }^{1}$ Department of Pharmaceutical Biochemistry, University of Medical Sciences, Świecickiego 4, 60-781 Poznań, Poland \\ ${ }^{2}$ Department of Food Chemistry, Technology and Biotechnology, Gdańsk University of Technology, Gdańsk, Poland \\ (Received 12 April 2010 - Revised 7 September 2010-Accepted 24 September 2010 - First published online 23 November 2010)
}

\section{Abstract}

The effect of raw cabbage and sauerkraut juices on the expression and activity of phase II enzymes, glutathione $S$-transferase (GST) and $\mathrm{NAD}(\mathrm{P}) \mathrm{H}$ :quinone oxidoreductase 1 (NQO1), in the rat liver and kidney was compared with that of two commercially available products of glucosinolate degradation: indole-3-carbinol (I3C) and phenethyl isothiocyanate (PEITC). Male Wistar rats were treated by oral administration with cabbage juices, I3C or PEITC for 4,10 and $30 \mathrm{~d}$. The results showed that juices, particularly sauerkraut juice as with I3C and PEITC, significantly increased GST and NQO1 activities in the rat liver. The only exception was the $30 \mathrm{~d}$ time point of feeding with raw cabbage juice. Cabbage juices, I3C and PEITC affected the hepatic GST $\mu$ to the greatest extent and GST $\alpha$ to a lesser extent. The results of the present study also showed that the treatment of rats with juices and compounds tested caused the translocation of the NF-E2-related transcription factor ( $\mathrm{Nrf} 2$ ) active subunit from the cytosol to the nucleus, providing an argument for the involvement of this transcription factor in the induction of GST and NQO1. In contrast to the liver, cabbage juices affected only the renal GST $\theta$, while treatment with I3C and PEITC significantly increased the activity of NQO1. Thus, the results of the present study indicate that induction of the key detoxifying enzymes by cabbage juices, particularly sauerkraut, may be responsible for their chemopreventive activity demonstrated by epidemiological studies and in animal models. However, the final effects might be organ or tissue dependent.

Key words: Cabbage juices: Indole-3-carbinol: Phenethyl isothiocyanate: NF-E2-related transcription factor: Phase II enzymes

Numerous epidemiological studies have demonstrated that consumption of Brassica vegetables such as Brussels sprouts, broccoli and cabbage has been associated with decreased incidence of several types of cancer ${ }^{(1,2)}$. Brassica vegetables are usually consumed in the processed form. They are subjected to technological and culinary processing, such as cutting, blanching, cooking and fermentation. Due to dietary habits, fermentation of vegetables, mainly white cabbage, has been limited only to some parts of the world ${ }^{(3)}$. Fermented cabbage is very popular in Poland and Germany, but is also consumed in the USA, Canada and Russia.

The most common product among fermented white cabbage is sauerkraut, which results from lactic acid fermentation of shredded and salted white cabbage.

Epidemiological data, although not so numerous as for the other cruciferous vegetables, indicate that consumption of processed cabbage might be related to reduced risk of breast, prostate and colorectal cancer ${ }^{(2)}$. Similar to other vegetables, Brassica contain a number of micronutrients (minerals: Mg, I, K and P; vitamins: C, E, K, $\alpha$-, $\beta$-carotene and folic acid) and phytochemicals such as polyphenols with chemopreventive properties. However, they are unique in that they are rich sources of glucosinolates (GLS). Depending on the type and conditions of processing, GLS undergo either enzymatic hydrolysis or thermal degradation resulting in the formation of biologically active compounds including indoles and isothiocyanates (ITC). The effect of fermentation on GLS degradation products has been poorly recognised ${ }^{(3,4)}$. The formation of some specific products such as ascorbigen is suggested ${ }^{(5)}$.

It is generally accepted that the breakdown products of GLS, particularly ITC, act through induction of phase II enzymes ${ }^{(2)}$.

Induction of phase II detoxifying and antioxidant enzymes such as glutathione $S$-transferase (GST) and $\mathrm{NAD}(\mathrm{P}) \mathrm{H}$ :quinone oxidoreductase 1 (NQO1) is the major

Abbreviations: GLS, glucosinolate; GST, glutathione $S$-transferase; I3C, indole-3-carbinol; ITC, isothiocyanate; NQO1, NAD(P)H:quinone oxidoreductase 1; Nrf2, NF-E2-related transcription factor; PEITC, phenethyl isothiocyanate.

*Corresponding author: Professor W. Baer-Dubowska, fax +48 61 8546620, email baerw@ump.edu.pl 
defence system in response to cell oxidative and electrophilic insults. Several lines of evidence clearly indicate that a coordinated regulation of the genes encoding phase II enzymes is mediated at the transcriptional level, by an NF-E2-related transcription factor (Nrf2) in part, by a cis-acting element in the promoter, i.e. the antioxidant-responsive element ${ }^{(6)}$. The induction of phase II enzymes, especially GST, which detoxifies xenobiotics and potential carcinogens by conjugation with glutathione, was closely correlated with the reduction in the number of chemically induced tumours in rodents ${ }^{(7)}$. Although very few studies have addressed induction of these enzymes by food components in human subjects or human cells, the study of Bogaards et al. ${ }^{(8)}$ demonstrated that a diet high in Brussels sprouts increased the level of plasma GST $\alpha$. This GST isoform may inactivate ultimate carcinogenic metabolites of carcinogenic polycyclic aromatic hydrocarbons. Thus, the modulation of these enzymes might be linked to the reduced risk of cancer among cabbage consumers.

The aim of the present study was to investigate the effect of long-term feeding (28d) with cabbage and sauerkraut juices on the GST and NOQ1 expressions and activities in the rat liver and kidney. In order to explore the mechanism of the possible modulation of their induction, the influence of cabbage juices on the activation of $\mathrm{Nrf} 2$ was also examined, and comparison with the effects of pure GLS degradation products, indole-3-carbinol (I3C) and phenethyl isothiocyanate (PEITC), was made.

Table 1. Effect of raw cabbage juice and sauerkraut juice on the activities of phase II enzymes in the rat liver

(Mean values with their standard errors, $n 6$ )

\begin{tabular}{|c|c|c|c|c|c|}
\hline \multirow{2}{*}{$\begin{array}{l}\text { Time } \\
\text { point (d) }\end{array}$} & \multirow[b]{2}{*}{ Treatment } & \multicolumn{2}{|c|}{$\mathrm{GST}^{\star} \dagger$} & \multicolumn{2}{|c|}{ NQO1‡ } \\
\hline & & Mean & SEM & Mean & SEM \\
\hline \multirow[t]{3}{*}{4} & Control & 540.06 & 14.98 & 78.91 & $4 \cdot 62$ \\
\hline & $\begin{array}{l}\text { Raw cabbage } \\
\text { juice }\end{array}$ & $668 \cdot 69 \|$ & $12.97(124) \S$ & $128 \cdot 62 \|$ & 6.59 (163) \\
\hline & $\begin{array}{l}\text { Sauerkraut } \\
\text { juice }\end{array}$ & $648 \cdot 07||$ & $23.42(120)$ & $122 \cdot 31 \|$ & 7.95 (155) \\
\hline \multirow[t]{3}{*}{10} & Control & 570.57 & $17 \cdot 29$ & 71.71 & 3.54 \\
\hline & $\begin{array}{l}\text { Raw cabbage } \\
\text { juice }\end{array}$ & $696 \cdot 10 \|$ & $17 \cdot 45(122)$ & $119.05 \|$ & $8.92(131)$ \\
\hline & $\begin{array}{l}\text { Sauerkraut } \\
\text { juice }\end{array}$ & $827 \cdot 33 \|$ & $20.56(145)$ & $95 \cdot 37 \| \uparrow$ & $9.56(133)$ \\
\hline \multirow[t]{3}{*}{30} & Control & 592.35 & 83.02 & 72.95 & 3.60 \\
\hline & $\begin{array}{l}\text { Raw cabbage } \\
\text { juice }\end{array}$ & $752 \cdot 28 \|$ & $20 \cdot 62(127)$ & $75 \cdot 64$ & 3.96 (103) \\
\hline & $\begin{array}{l}\text { Sauerkraut } \\
\text { juice }\end{array}$ & $992 \cdot 73 \| \mathbb{1}$ & $45 \cdot 82(168)$ & $111 \cdot 61 \| 9$ & $7 \cdot 65$ (153) \\
\hline
\end{tabular}

GST, glutathione $S$-transferase; NQO1, NAD(P)H:quinone oxidoreductase 1.

*Each assay was run in triplicate.

†GST is expressed in nmol 1-chloro-2,4-dinitrobenzene conjugated formed/min per mg.

‡NQO1 is expressed in nmol 2,6-dichloroindophenol reduced/min per $\mathrm{mg}$.

§ Percentage of control.

$\|$ Mean values were significantly different from the control group $(P<0.05)$.

I Mean values were significantly different from the raw cabbage juice group $(P<0.05)$.
Table 2. Effect of indole-3-carbinol (I3C) on the activities of phase II enzymes in the rat liver

(Mean values with their standard errors, $n 6$ )

\begin{tabular}{|c|c|c|c|c|c|}
\hline \multirow{2}{*}{$\begin{array}{l}\text { Time } \\
\text { point (d) }\end{array}$} & \multirow[b]{2}{*}{ Treatment } & \multicolumn{2}{|c|}{$\mathrm{GST}^{*} \dagger$} & \multicolumn{2}{|c|}{ NQ01‡ } \\
\hline & & Mean & SEM & Mean & SEM \\
\hline \multirow[t]{2}{*}{4} & Control & 655.66 & $29 \cdot 22$ & 73.87 & $2 \cdot 87$ \\
\hline & I3C & $1055 \cdot 61 \|$ & $49 \cdot 27(161) \S$ & $133.57 \|$ & 7.74 (181) \\
\hline \multirow[t]{2}{*}{10} & Control & 588.98 & 43.63 & 69.17 & 4.37 \\
\hline & I3C & $854.02 \|$ & $37 \cdot 28$ (145) & $130 \cdot 09 \|$ & $5 \cdot 24$ (188) \\
\hline \multirow[t]{2}{*}{30} & Control & $625 \cdot 76$ & 41.90 & $75 \cdot 76$ & $6 \cdot 19$ \\
\hline & I3C & $932 \cdot 38 \|$ & 32.52 (149) & $145 \cdot 93 \|$ & $13.76(193)$ \\
\hline
\end{tabular}

GST, glutathione S-transferase; NQO1, NAD(P)H:quinone oxidoreductase 1.

${ }^{*}$ Each assay was run in triplicate.

†GST is expressed in nmol 1-chloro-2,4-dinitrobenzene conjugated formed/min per mg.

‡NQO1 is expressed in nmol 2,6-dichloroindophenol reduced/min per mg

$\S$ Percentage of control.

\|l Mean values were significantly different from the control group $(P<0.05)$.

\section{Experimental methods}

\section{Chemicals}

I3C, glutathione, 1-chloro-2,4-dinitrobenzene, 2,6-dichlorophenolindophenol, dicoumarol, NADPH, dithiothreitol, sucrose, bovine serum albumin, PEITC and Tris were purchased from Sigma Chemicals Company (St Louis, MO, USA). Primary antibodies against $\beta$-actin and NQO1 and secondary antibodies were supplied by Santa Cruz Biotechnology (Santa Cruz, CA, USA). Primary antibodies against GST $\alpha$, GST $\pi$ and GST $\mu$, purified standards of GST $\pi$ and secondary antibodies were supplied by Oxford Biomedical Research (Oxford, MI, USA). Primary and secondary antibodies against GST $\theta$ were obtained from LabAs Limited (Tartu, Estonia). All antibodies used in these experiments were specific for their respective proteins, and according to the information provided by suppliers, there was no cross-reactivity within the isozymes of

Table 3. Effect of phenethyl isothiocyanate (PEITC) on the activities of phase II enzymes in the rat liver

(Mean values with their standard errors, $n 6$ )

\begin{tabular}{|c|c|c|c|c|c|}
\hline \multirow{2}{*}{$\begin{array}{l}\text { Time } \\
\text { point (d) }\end{array}$} & \multirow[b]{2}{*}{ Treatment } & \multicolumn{2}{|c|}{$\mathrm{GST}^{*} \dagger$} & \multicolumn{2}{|c|}{ NQ01‡ } \\
\hline & & Mean & SEM & Mean & SEM \\
\hline \multirow[t]{2}{*}{4} & Control & $520 \cdot 15$ & 7.32 & 89.55 & $6 \cdot 63$ \\
\hline & PEITC & $838 \cdot 24 \|$ & $39.28(161) \S$ & $190 \cdot 74 \|$ & $11.86(213)$ \\
\hline \multirow[t]{2}{*}{10} & Control & 619.51 & 15.57 & 81.95 & 11 \\
\hline & PEITC & $841.58 \|$ & 31.39 (136) & $179 \cdot 47 \|$ & $10.32(219)$ \\
\hline \multirow[t]{2}{*}{30} & Control & $636 \cdot 79$ & $9 \cdot 30$ & 79.98 & 3.81 \\
\hline & PEITC & $971 \cdot 27 \|$ & $25 \cdot 49$ (153) & $162 \cdot 36 \|$ & $10 \cdot 38(203)$ \\
\hline
\end{tabular}

GST, glutathione S-transferase; NQO1, NAD(P)H:quinone oxidoreductase 1.

${ }^{*}$ Each assay was run in triplicate.

†GST is expressed in nmol 1-chloro-2,4-dinitrobenzene conjugated formed/min per mg.

‡NQO1 is expressed in nmol 2,6-dichloroindophenol reduced/min per mg

§ Percentage of control.

$\|$ Mean values were significantly different from the control group $(P<0.05)$. 
the same family. Rainbow-coloured protein molecular weight marker was purchased from Amersham Pharmacia Biotechnology (Piscataway, NJ, USA). All other chemicals were commercial products of the highest purity available.

\section{Animals and treatments}

Male Wistar rats (6 weeks of age), provided by University of Medical Sciences, Department of Toxicology Breeding Facility (Poznań, Poland), were housed in polycarbonate cages $(30 \times 20 \times 25 \mathrm{~cm}$; $\leq$ four rats/cage), containing hardwood chip bedding. Commercial rat food (Altromin $\mathrm{GmbH}$, Lage, Germany) and distilled water were available without restriction. Six animals (average body weight $250 \mathrm{~g}$ ) were used for each of twenty-one experimental groups characterised in Tables 1-6. The animals were treated by oral administration (intragastric) with cabbage and sauerkraut juices $(1.25 \mathrm{ml} / \mathrm{kg}$ body weight), I3C $(100 \mathrm{mg} / \mathrm{kg}$ body weight) or PEITC $(100 \mathrm{mg} / \mathrm{kg}$ body weight) for 4,10 and $30 \mathrm{~d}$.

The doses were selected based on the protocols of Zhang \& Malejka-Giganti ${ }^{(9,)}$ and Adam-Rodwell et al. ${ }^{(10)}$. Control groups of animals received water, or $20 \%$ ethanol in olive oil, or olive oil, respectively. All animals were killed $24 \mathrm{~h}$ after the last treatment. Ketamine (intramuscular injection, $130 \mathrm{mg} / \mathrm{kg}$ body weight) was used as an anaesthetic.

All procedures were carried out according to the European guidelines for the care and use of laboratory animals and were approved by the Regional Ethics Committee (no. 36/2008).

Table 4. Effect of raw cabbage juice and sauerkraut juice on the activities of phase II enzymes in rat kidney

(Mean values with their standard errors, $n 6$ )

\begin{tabular}{|c|c|c|c|c|c|}
\hline \multirow{2}{*}{$\begin{array}{l}\text { Time } \\
\text { point (d) }\end{array}$} & \multirow[b]{2}{*}{ Treatment } & \multicolumn{2}{|c|}{ GST*† } & \multicolumn{2}{|c|}{ NQO1‡ } \\
\hline & & Mean & SEM & Mean & SEM \\
\hline \multirow[t]{3}{*}{4} & Control & $180 \cdot 12$ & $20 \cdot 62$ & 34.69 & $2 \cdot 11$ \\
\hline & $\begin{array}{l}\text { Raw cabbage } \\
\text { juice }\end{array}$ & $221 \cdot 55 \|$ & $18.91(123) \S$ & $57 \cdot 61 \|$ & $6 \cdot 13(166)$ \\
\hline & $\begin{array}{l}\text { Sauerkraut } \\
\text { juice }\end{array}$ & $230 \cdot 55 \|$ & $24 \cdot 74(128)$ & $61 \cdot 06 \|$ & $5 \cdot 62(176)$ \\
\hline \multirow[t]{3}{*}{10} & Control & $153 \cdot 67$ & $17 \cdot 29$ & $37 \cdot 11$ & $5 \cdot 37$ \\
\hline & $\begin{array}{l}\text { Raw cabbage } \\
\text { juice }\end{array}$ & $168 \cdot 93$ & $28 \cdot 88(110)$ & $47 \cdot 13 \|$ & $1.90(127)$ \\
\hline & $\begin{array}{l}\text { Sauerkraut } \\
\text { juice }\end{array}$ & $152 \cdot 03$ & 23.48 (99) & $51 \cdot 58 \|$ & $1 \cdot 38(139)$ \\
\hline \multirow[t]{3}{*}{30} & Control & $189 \cdot 75$ & $9 \cdot 69$ & 32.95 & $6 \cdot 04$ \\
\hline & $\begin{array}{l}\text { Raw cabbage } \\
\text { juice }\end{array}$ & 204.93 & $11 \cdot 19(108)$ & $28 \cdot 66$ & $1.50(87)$ \\
\hline & $\begin{array}{l}\text { Sauerkraut } \\
\text { juice }\end{array}$ & 195.44 & $13 \cdot 37(103)$ & $31 \cdot 30$ & $1.05(95)$ \\
\hline
\end{tabular}

GST, glutathione S-transferase; NQO1, NAD(P)H:quinone oxidoreductase 1.

*Each assay was run in triplicate.

†GST is expressed in nmol 1-chloro-2,4-dinitrobenzene conjugated formed/min per mg.

‡NQO1 is expressed in nmol 2,6-dichloroindophenol reduced/min per mg $\S$ Percentage of control.

\| Mean values were significantly different from the control group $(P<0.05)$.
Table 5. Effect of indole-3-carbinol (I3C) on the activities of phase II enzymes in rat kidney

(Mean values with their standard errors, $n 6$ )

\begin{tabular}{|c|c|c|c|c|c|}
\hline \multirow{2}{*}{$\begin{array}{l}\text { Time } \\
\text { point (d) }\end{array}$} & \multirow[b]{2}{*}{ Treatment } & \multicolumn{2}{|c|}{$\mathrm{GST}^{*} \dagger$} & \multicolumn{2}{|c|}{ NQO1‡ } \\
\hline & & Mean & SEM & Mean & SEM \\
\hline \multirow[t]{2}{*}{4} & Control & $178 \cdot 43$ & 3.54 & $24 \cdot 42$ & 0.99 \\
\hline & I3C & $206 \cdot 31$ & $10 \cdot 86(116) \S$ & $37 \cdot 88 \|$ & $1.06(155)$ \\
\hline \multirow[t]{2}{*}{10} & Control & 180.59 & 6.57 & $25 \cdot 84$ & 0.45 \\
\hline & I3C & $200 \cdot 51$ & $10 \cdot 30(111)$ & $34 \cdot 55 \|$ & $1.45(134)$ \\
\hline \multirow[t]{2}{*}{30} & Control & 185.53 & $10 \cdot 32$ & 25.63 & $1 \cdot 76$ \\
\hline & I3C & 210.97 & $6 \cdot 64(114)$ & $36 \cdot 42 \|$ & $2 \cdot 17(142)$ \\
\hline
\end{tabular}

GST, glutathione S-transferase; NQO1, NAD(P)H:quinone oxidoreductase 1.

${ }^{*}$ Each assay was run in triplicate.

†GST is expressed in nmol 1-chloro-2,4-dinitrobenzene conjugated formed/min per mg.

‡NQO1 is expressed in nmol 2,6-dichloroindophenol reduced/min per $\mathrm{mg}$

$\S$ Percentage of control.

II Mean values were significantly different from the control group $(P<0.05)$.

\section{Preparation of juices}

Fresh white cabbage was purchased in a wholesale shop supplying the area of Gdańsk in vegetables. After removal of outer leaves, cabbage heads were cut in a shredder into approximately $2 \mathrm{~mm}$ thick strips. The part of shredded cabbage was blended, and the juice was squeezed out from the pulps. The rest of the shredded cabbage was subjected to a fermentation process. The shredded cabbage was mixed with $20 \mathrm{~g} / \mathrm{kg}$ of $\mathrm{NaCl}$ and fermented in a traditional stoneware pot for 2 weeks. The juice standardisation was performed according to previously published protocols ${ }^{(11)}$. In fresh juice, the average content of ITC groups and I3C was 0.15 and $2.74 \mu \mathrm{mol} / 1$, respectively. In sauerkraut juice, the content of I3C was below the level of detection, while the level of ITC was not determined.

Table 6. Effect of phenethyl isothiocyanate (PEITC) on the activities of phase II enzymes in rat kidney

(Mean values with their standard errors, $n 6$ )

\begin{tabular}{|c|c|c|c|c|c|}
\hline \multirow{2}{*}{$\begin{array}{l}\text { Time } \\
\text { point (d) }\end{array}$} & \multirow[b]{2}{*}{ Treatment } & \multicolumn{2}{|c|}{ GST $^{*} \dagger$} & \multicolumn{2}{|c|}{ NQO1‡ } \\
\hline & & Mean & SEM & Mean & SEM \\
\hline \multirow[t]{2}{*}{4} & Control & $105 \cdot 67$ & $2 \cdot 71$ & $19 \cdot 54$ & 0.73 \\
\hline & PEITC & $139 \cdot 29 \|$ & $5.46(132) \S$ & $29.94 \|$ & $1 \cdot 28(153)$ \\
\hline \multirow[t]{2}{*}{10} & Control & $106 \cdot 97$ & $2 \cdot 93$ & $19 \cdot 42$ & 0.45 \\
\hline & PEITC & $133 \cdot 00 \|$ & $2 \cdot 70(124)$ & 34.08\| & $1.22(175)$ \\
\hline \multirow[t]{2}{*}{30} & Control & $112 \cdot 81$ & $2 \cdot 81$ & 24.94 & 0.75 \\
\hline & PEITC & 119.55 & $2 \cdot 96$ (106) & $46 \cdot 48 \|$ & $1.42(186)$ \\
\hline
\end{tabular}

GST, glutathione $S$-transferase; NQO1, NAD(P)H:quinone oxidoreductase 1.

* Each assay was run in triplicate.

†GST is expressed in nmol 1-chloro-2,4-dinitrobenzene conjugated formed/min per mg.

‡NQO1 is expressed in nmol 2,6-dichloroindophenol reduced/min per $\mathrm{mg}$ $\S$ Percentage of control.

II Mean values were significantly different from the control group $(P<0.05)$. 


\section{Preparation of cytosolic fractions}

At $24 \mathrm{~h}$ after the last treatment, the rats were killed by decapitation, and the liver and kidneys were removed. The tissues were rinsed in the ice-cold buffered $0 \cdot 2 \mathrm{~m}$-sucrose $(\mathrm{pH} 7 \cdot 5)$ and homogenised in the same medium. For the determination of enzyme activities, the cytosolic fraction was prepared by differential centrifugation, and protein concentrations were determined as described previously ${ }^{(12)}$.

\section{Preparation of nuclear extracts from the rat liver}

The cytosolic and nuclear extracts from the rat liver were prepared by using a Nuclear/Cytosol Fractionation Kit (BioVision Research, Mount View, CA, USA).

\section{Enzyme activity assay}

The activities of cytosolic NQO1 (assayed with NADPH as the electron donor and 2,6-dichlorophenolindophenol as the electron acceptor) and GST, using 1-chloro-2,4-dinitrobenzene as a substrate, were determined using protocols described in our earlier studies ${ }^{(12)}$.

\section{Protein immunoblotting}

Cytosolic proteins $(20-100 \mu \mathrm{g})$ were separated on 10 or $12 \%$ SDS-PAGE slab gels, and the proteins were transferred to nitrocellulose membranes (Immobilon-P; Millipore, Bedford, MA, USA) ${ }^{(13)}$. After blocking with $10 \%$ skimmed milk, the proteins were probed with rabbit anti-human GST $\alpha$, goat anti-rat GST $\mu$, rabbit anti-human GST $\pi$, human anti-mouse GST $\theta$, goat anti-human NQO1, rabbit antimouse Nrf2 and rabbit anti-mouse $\beta$-actin antibodies. The $\beta$-actin protein was used as an internal control. As the secondary antibodies in the staining reaction, the alkaline phosphatase-labelled anti-goat IgG, anti-mouse IgG or anti-rabbit IgG were used. The amount of the immunoreactive product in each lane was determined by densitometric scanning using a BioRad GS 710 Image Densitometer (BioRad Laboratories, Hercules, CA, USA). The values were calculated as relative absorbance units $(\mathrm{RQ}) / \mathrm{mg}$ protein.

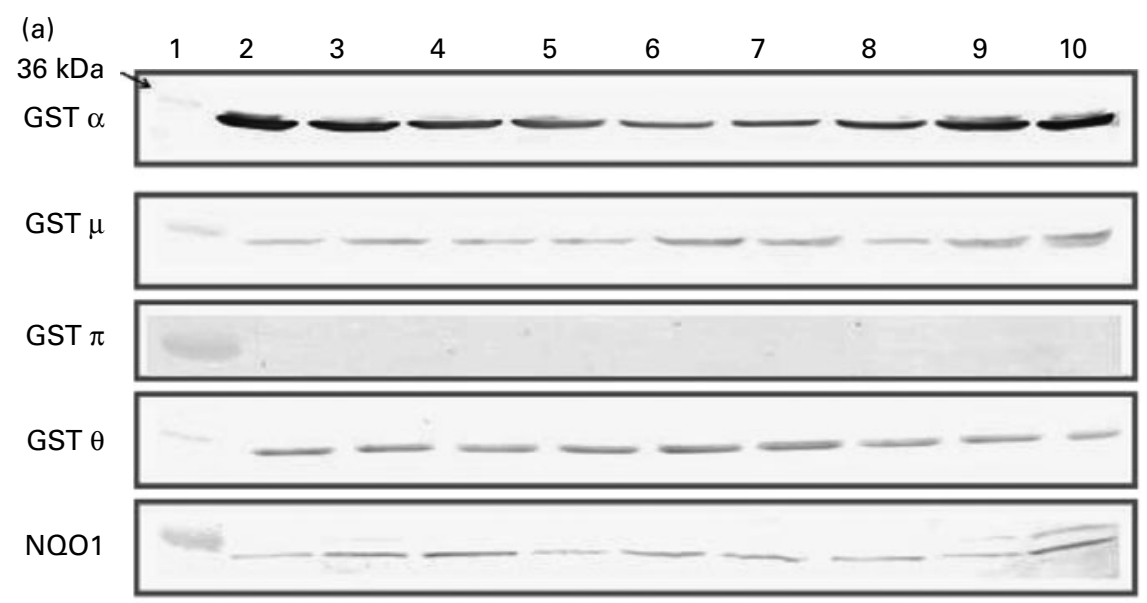

(b)

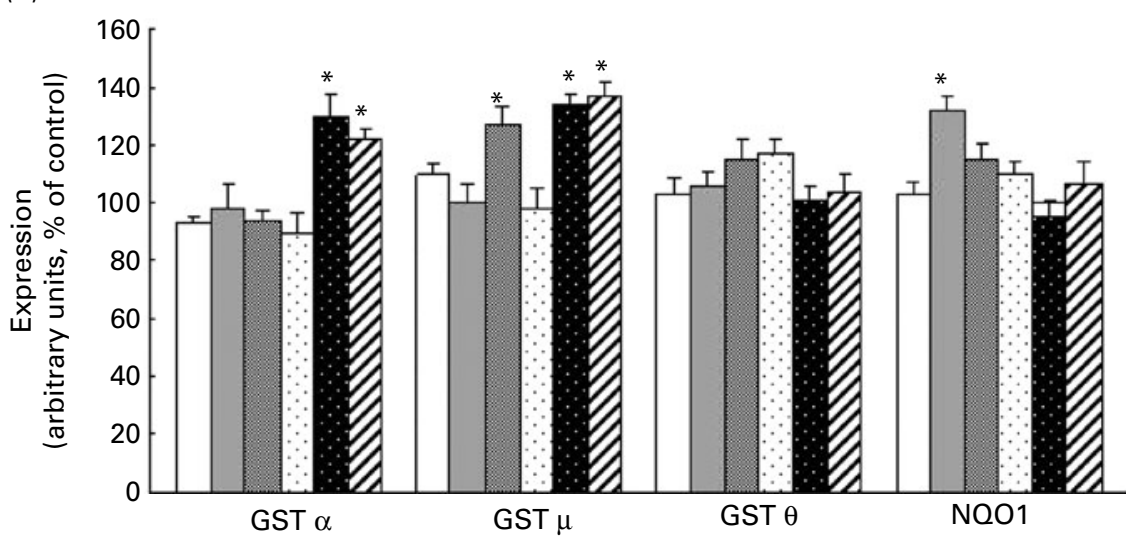

Fig. 1. Expression of glutathione $S$-transferase (GST) isozymes and $N A D(P) H: q u i n o n e$ oxidoreductase 1 (NQO1) in the rat liver treated with cabbage juices. (a) A representative immunoblot from two independent experiments. (b) Data presented as percentage of control groups (means with their standard errors) from two separate experiments run in triplicate. * Mean values were significantly different from the control group $(P<0.05)$. Lane 1 , molecular weight marker; lane 2 , control (4 d); lane 3, raw cabbage juice (RCJ; 4 d, $\square$ ); lane 4, sauerkraut juice (SJ; 4 d, $\square$ ); lane 5, control (10 d); lane 6, RCJ (10 d, 圈); lane 7, SJ (10 d, $\square$ ); lane 8,

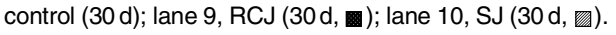


(a)
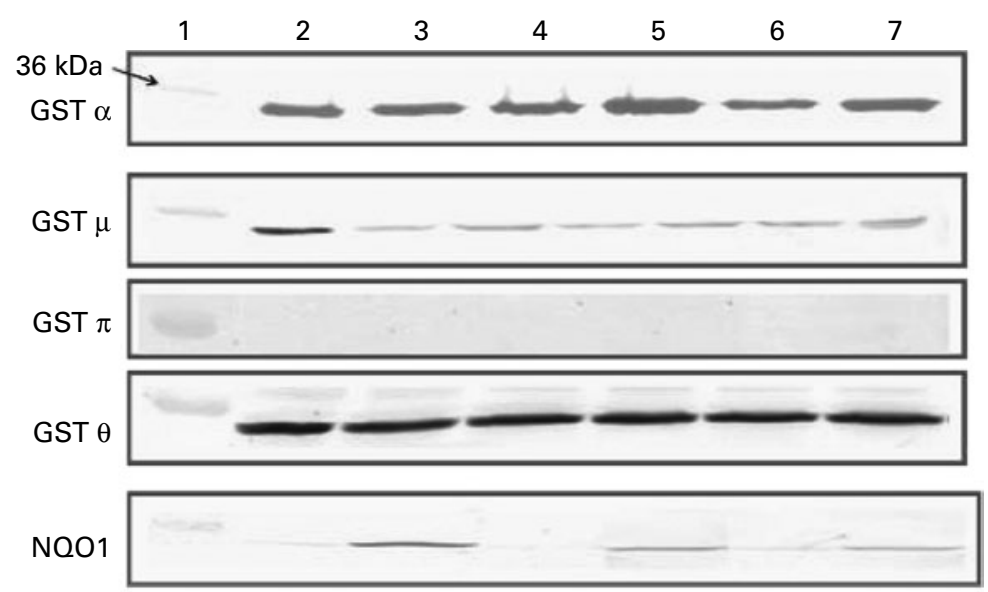

(b)

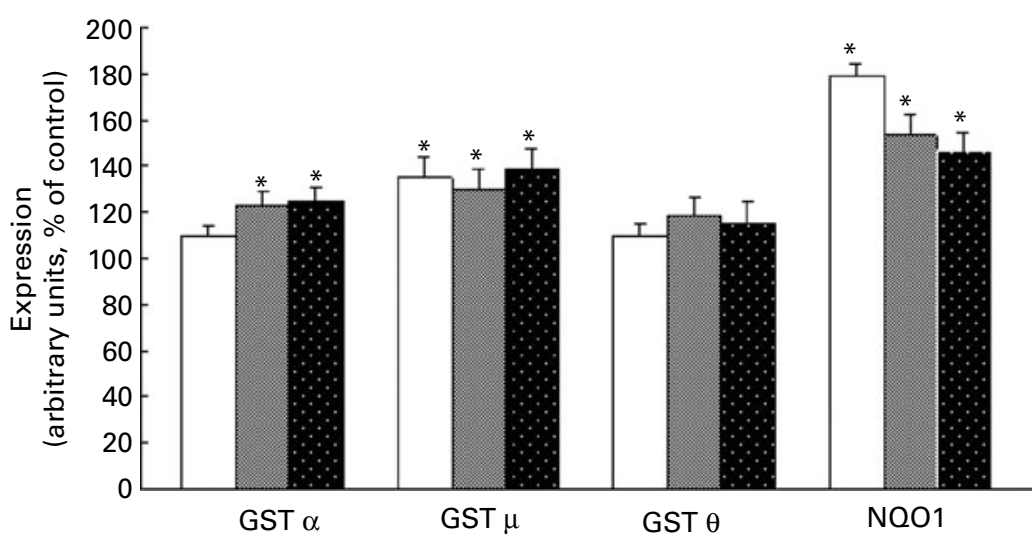

Fig. 2. Expression of glutathione $S$-transferase (GST) isozymes and $\mathrm{NAD}(\mathrm{P}) \mathrm{H}$ :quinone oxidoreductase 1 (NQO1) in the rat liver treated with indole-3-carbinol (I3C). (a) A representative immunoblot from two independent experiments. (b) Data presented as percentage of control groups (means with their standard errors) from two separate experiments run in triplicate. * Mean values were significantly different from the control group $(P<0 \cdot 05)$. Lane 1 , molecular weight marker; lane 2 ,

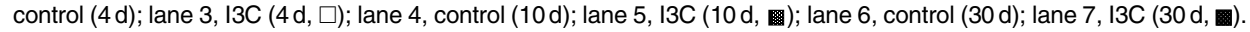

\section{Statistical analysis}

Statistical analysis was performed by one-way ANOVA. Statistical significance between the experimental groups and their respective controls was assessed by Tukey's post hoc test at $P<0.05$.

\section{Results}

Effect of raw cabbage and sauerkraut juices, indole-3carbinol and phenethyl isothiocyanate on phase II enzyme activity in the rat liver and kidney

The effects of intragastric treatment with cabbage juices on GST and NQO1 in the rat liver are summarised in Table 1. Feeding with raw cabbage juice increased the activity of both enzymes except the $30 \mathrm{~d}$ time point. The sauerkraut juice, however, enhanced more significantly the activity of these enzymes in all time points of treatment. The most significant difference was noted in the case of GST and NQO1 after $30 \mathrm{~d}$ of feeding. At this time point, a 68 and $53 \%$ increase in the GST and NQO1 activity, respectively, was observed, while raw cabbage juice did not change the activity of NQO1 and only slightly changed (by $27 \%$ ) GST activity. The increase in the GST activity by sauerkraut was similar to that observed as a result of treatment with I3C (Table 2) and PEITC (Table 3). The NQO1 activity, however, was less affected by sauerkraut juice in comparison with these two compounds. Statistical analysis showed the significant effect of sauerkraut juice on NQO1 activity after 10 and $30 \mathrm{~d}$, while GST was affected only after $30 \mathrm{~d}$ of treatment (Table 1).

In the kidney, the increase in GST activity was observed after $4 \mathrm{~d}$ of raw cabbage (23\%) and sauerkraut juices (28\%) and the activity of NQO1 on the 10th day of feeding with both juice (27 and 37\%) treatments (Table 4).

I3C (Table 5) significantly increased the activity of NQO1 at all time points. The most effective inducer of NQO1 in this tissue was PEITC, which increased the activity of this enzyme by $86 \%$ on the 30th day of treatment with this compound. The increased (24-32\%) activity of GST was also observed only as a result of 4 and $10 \mathrm{~d}$ treatment with PEITC (Table 6). 
(a)

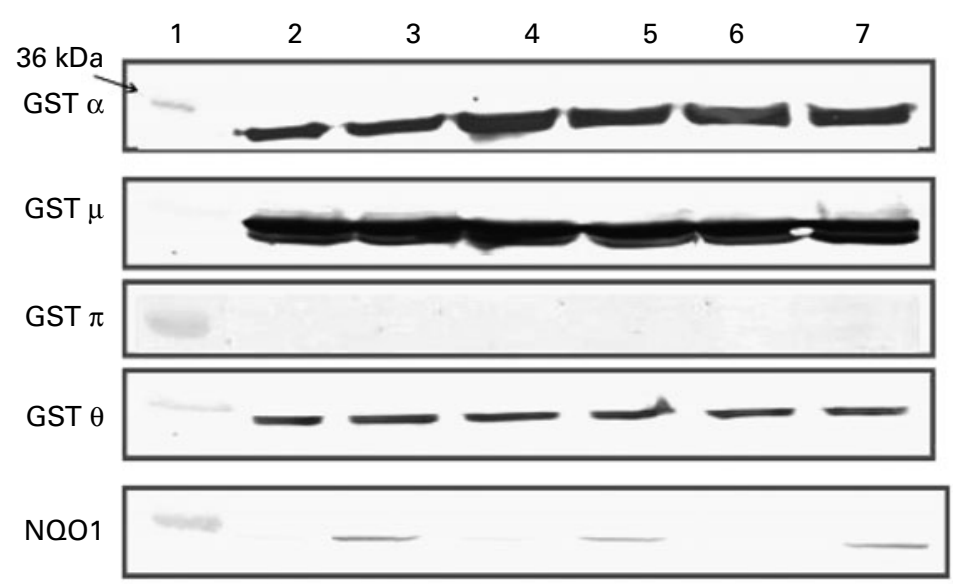

(b)

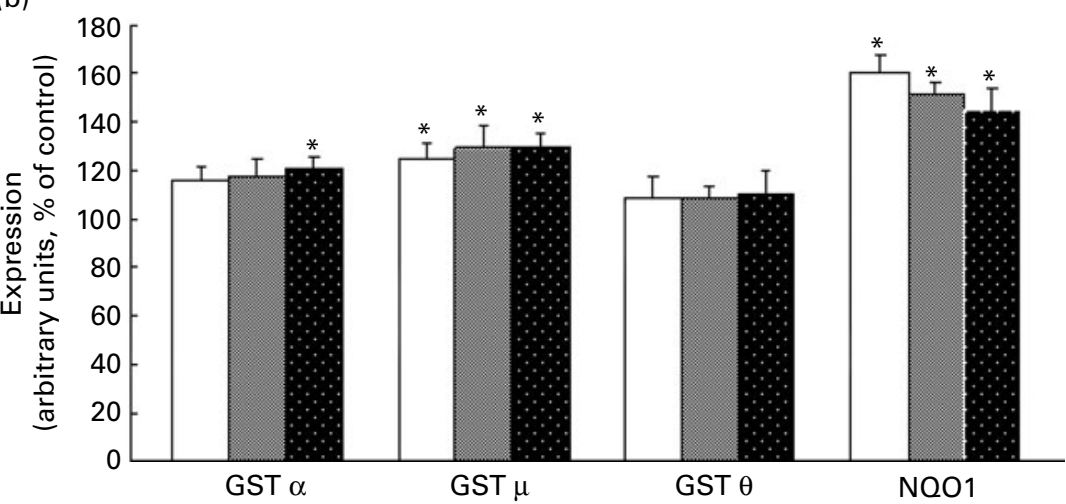

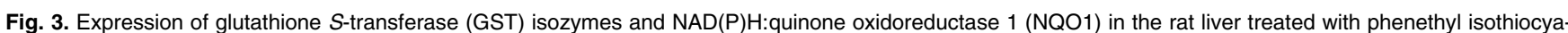
nate (PEITC). (a) A representative immunoblot from two independent experiments. (b) Data presented as percentage of control groups (means with their standard errors) from two separate experiments run in triplicate. * Mean values were significantly different from the control group $(P<0.05)$. Lane 1 , molecular weight marker; lane 2, control (4 d); lane 3, PEITC (4 d, $\square$ ); lane 4, control (10 d); lane 5, PEITC (10 d, 娄); lane 6, control (30 d); lane 7, PEITC (30 d, $\mathbf{m})$.

Effect of raw cabbage and sauerkraut juices, indole-3carbinol and phenethyl isothiocyanate on glutathione $S$-transferase isozymes and NAD $(P) H$ :quinone oxidoreductase 1 protein levels in the rat liver and kidney

Figs. 1(a), 2(a) and 3(a) show the immunoblots of GST isozymes and NQO1 in the liver of rats treated with cabbage juice and I3C or PEITC, respectively. On the basis of our ${ }^{(13)}$ and other ${ }^{(14)}$ results showing the lack of GST $\pi$ in the rat liver, only GST $\alpha, \mu$ and $\theta$ were analysed.

The quantitative analysis (Figs. 1(b), 2(b) and 3(b)) of the immunoblots revealed that both cabbage and sauerkraut juices similarly, as with $\mathrm{I} 3 \mathrm{C}$ and PEITC, increased the level of GST $\mu$ and to a lesser extent GST $\alpha$. However, the effect of cabbage juices was observed only after $30 \mathrm{~d}$ of feeding, while I3C and PEITC increased the levels of both GST isozymes at all time points examined. Hepatic GST $\theta$ was not affected by any treatment regimen.

In concert with the enhanced activity of NQO1, I3C and PEITC increased the enzyme protein level. Sauerkraut juice increased the NQO1 level only on the 4th day of treatment.

In the kidney (Figs. 4-6), neither cabbage juices nor I3C or PEITC affected the expression of GST isozymes and NQO1. The only exception was the reduced level of
GST $\theta$ observed on the 30th day of feeding with both raw cabbage and sauerkraut juices (Fig. 4).

Activation of NF-E2-related transcription factor in the rat liver by cabbage juice, indole-3-carbinol and phenethyl isothiocyanate

As shown in Fig. 7, the treatment with both cabbage and sauerkraut juices or I3C and PEITC led to the translocation of Nrf2 protein from the cytosol to the nucleus in the cells of the rat liver, increasing its level in the nuclear fraction. Quantitative analysis (Fig. 7(b)) revealed a significant increase in the amount of $\mathrm{Nrf} 2$ in the nucleus only on the 30th day of feeding with raw cabbage juice. Activation of Nrf2 by I3C and PEITC was observed at all time points studied, resulting in a $21-35 \%$ increase of this protein in the nucleus (Fig. 7(b)).

\section{Discussion}

Epidemiological studies have demonstrated that consumption of Brassica vegetables is associated with a lower incidence of cancers ${ }^{(15)}$. 

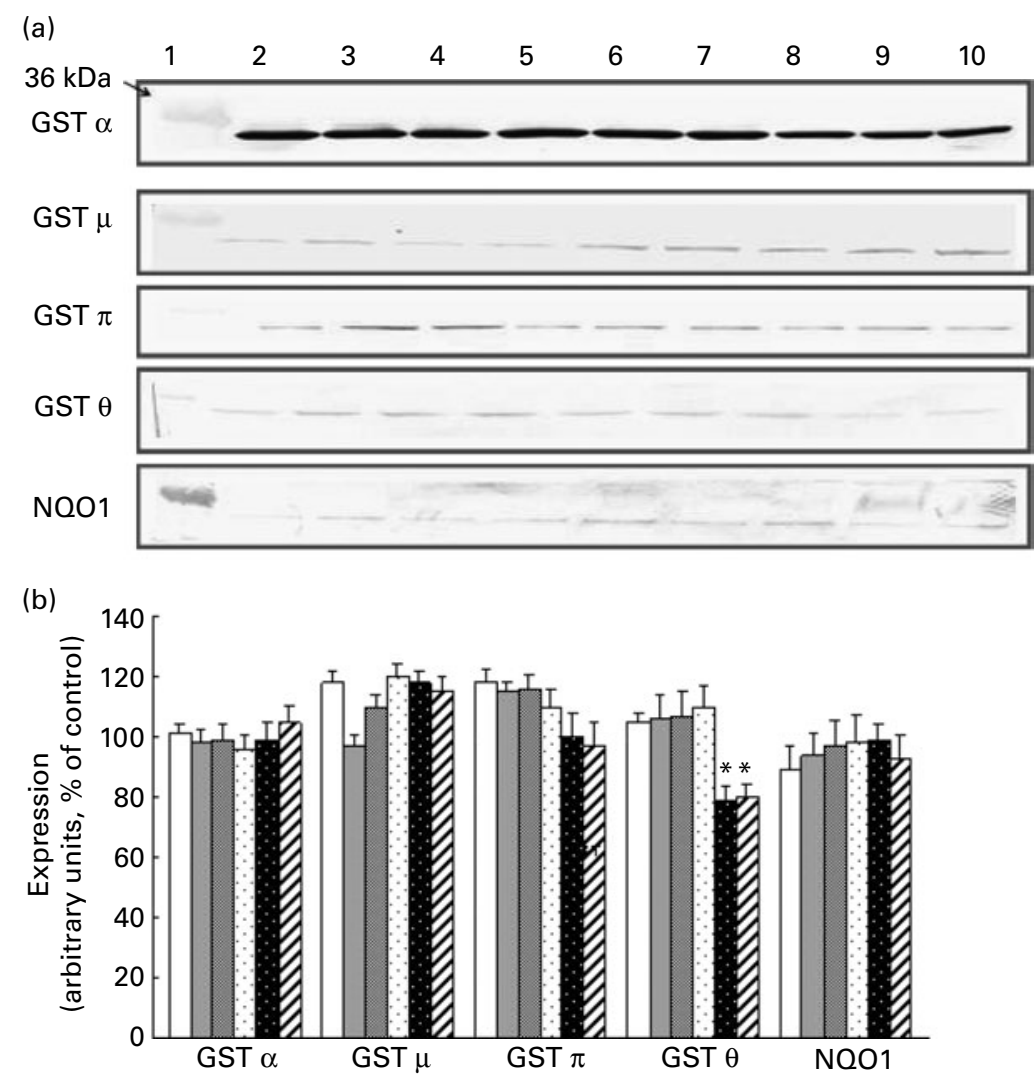

Fig. 4. Expression of glutathione $S$-transferase (GST) isozymes and $N A D(P) H$ :quinone oxidoreductase 1 (NQO1) in rat kidney treated with cabbage juices. (a) A representative immunoblot from two independent experiments. (b) Data presented as percentage of control groups (means with their standard errors) from two separate experiments run in triplicate. ${ }^{*}$ Mean values were significantly different from the control group $(P<0.05)$. Lane 1 , molecular weight marker; lane 2 , control (4 d); lane 3, raw cabbage juice (RCJ; $4 \mathrm{~d}, \square$ ); lane 4, sauerkraut juice (SJ; $4 \mathrm{~d}, \square$ ); lane 5, control (10 d); lane 6, RCJ (10d, 图); lane 7, SJ (10 d, $\square$ ); lane 8, control (30 d); lane 9, RCJ (30 d, 道); lane 10, SJ (30 d, 圆).

In the Central and Eastern European diet, the most common Brassica genus is white cabbage and its fermented product, sauerkraut. However, in contrast to other Cruciferae representatives, the anti-carcinogenic activity of white cabbage and sauerkraut has been less extensively studied. Epidemiological migrant studies have shown that consumption of these food items during adolescence was associated with a $72 \%$ reduced risk of breast cancer ${ }^{(16)}$. The lower risk of prostate and pancreatic cancers was also associated with cabbage consumption ${ }^{(17,18)}$.

The reduced risk of cancer as a result of Brassica vegetable consumption is usually linked to the dietary intake of GLS and their metabolism to cancer-preventive indoles (e.g. I3C) and ITC, such as PEITC. Their content and characteristics depend on a particular Brassica vegetable and its processing. Moreover, experimental studies have suggested the modulation of phase I and, particularly, phase II metabolising enzymes as one mechanism for the GLS association with anticancer protection.

Thus, the focus of the present study was to evaluate the effect of raw cabbage and sauerkraut juices on the induction of two phase II enzymes GST and NQO1.

The results show that raw cabbage and sauerkraut juices, as with I3C and PEITC treatments, increased GST and
NQO1 protein levels in the rat liver and subsequently the enzyme activities.

A significant effect was observed as a result of sauerkraut feeding in the rat liver, where a time-dependent induction of GST activity was observed. This effect was comparable with that exerted by pure I3C and PEITC. The latter observation concerning pure ITC is in agreement with the general opinion that GST are induced by these products of GLS degradation and act to conjugate this class of phytochemicals found in Brassica vegetables ${ }^{(2)}$. The level of the GST induction after the treatment with raw cabbage juice was lower and did not depend on the time point of juice intake.

Sauerkraut is the product of lactic acid fermentation of shredded and salted white cabbage. During shredding, glucobrassicin, the most commonly studied GLS, is transformed into I3C by the action of myrosinase. During fermentation, as the $\mathrm{pH}$ decreases, this indole reacts non-enzymatically with L-ascorbic acid to yield ascorbigen, which is thought to be the dominant end product of indole GLS in sauerkraut ${ }^{(3,5)}$.

While the effects of I3C have been extensively studied, only a few experiments focusing on the anti-carcinogenic effects of ascorbigen have been published. The data 


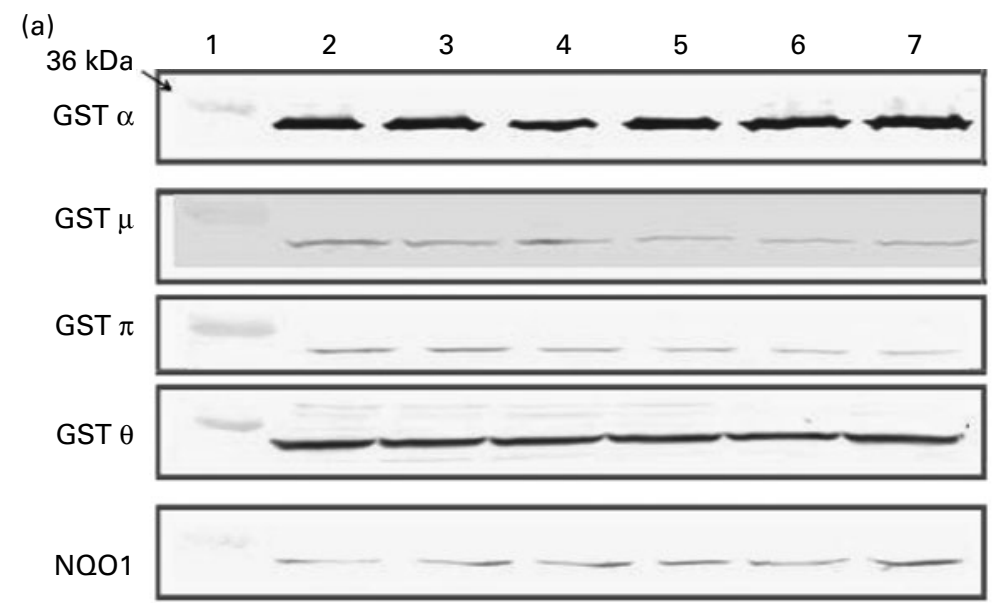

(b)

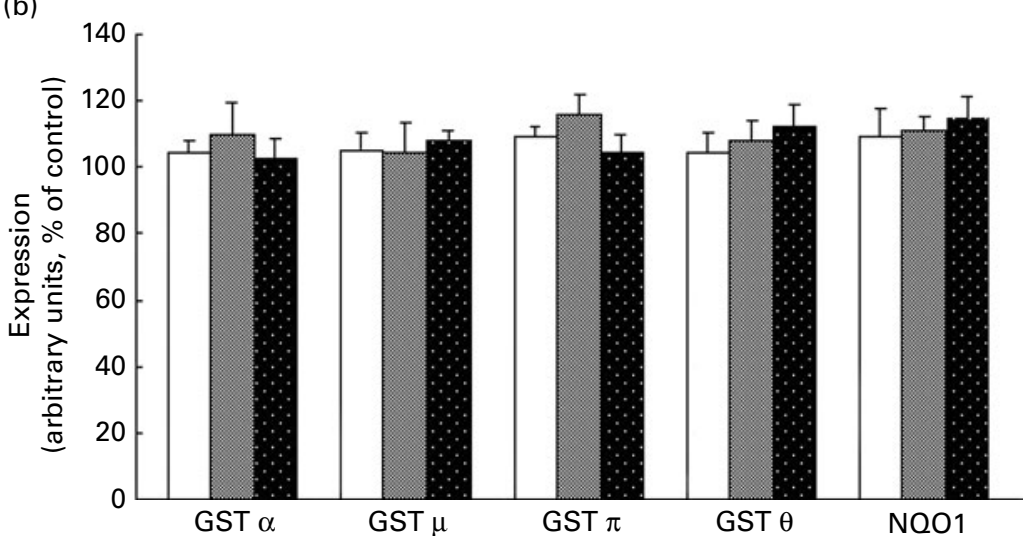

Fig. 5. Expression of glutathione $S$-transferase (GST) isozymes and NAD(P)H:quinone oxidoreductase 1 (NQO1) in rat kidney treated with indole-3-carbinol (I3C). (a) A representative immunoblot from two independent experiments. (b) Data presented as percentage of control groups (means with their standard errors) from two separate experiments run in triplicate. Lane 1, molecular weight marker; lane 2, control (4 d); lane 3, I3C (4 d, $\square$ ); lane 4, control (10 d); lane 5, I3C (10 d, 函); lane 6, control (30 d); lane 7, I3C (30 d, 圖).

provided by Stephenson et al. ${ }^{(19)}$ and Kravchenko et al. ${ }^{(20)}$ have shown that ascorbigen itself or in combination with the other degradation products (I3C and sulphoraphane) modulates the enzymes involved in xenobiotic metabolism, inducing also GST and NQO1. The interaction of ascorbigen with an aryl hydrocarbon receptor has been suggested $^{(20)}$ as the mechanism of induction.

The present results indicate that although interaction with an aryl hydrocarbon receptor cannot be excluded particularly for $\mathrm{I3C}$, which is a known bifunctional inducer, the induction of GST and NQO1 by cabbage juices occurred rather as a result of Nrf2 activation and binding to the antioxidant-responsive element in nuclear DNA. This assumption is based on the fact that both juices, as well as I3C and PEITC, caused a parallel increase in GST, NQO1 and Nrf2 protein levels.

$\mathrm{Nrf} 2$ plays a key role in the transcriptional regulation of GST and NQO1 expression through interaction with antioxidant response element. Under normal physiological conditions, Nrf2 is sequestered in the cytoplasm as an inactive complex with its repressor Keap $1^{(21)}$. Upon stimulation by inducers, Nrf2 dissociates from Keap1 and translocates into the nucleus where it dimerises with some cofactors such as small Maf protein and binds to antioxidant-responsive element. This leads to the activation of a battery of highly specialised proteins, including NQO1 and GST, and other antioxidant enzymes, such as glutamate cysteine ligase, haem oxygenase-1, that efficiently protect mammalian cells from various forms of toxicants and consequently reduce the propensity of tissues and organs to develop malignancies and other ailments ${ }^{(22)}$.

The results of the present study showing that treatment of rats with cabbage juices, I3C and PEITC caused the translocation of the Nrf2-active subunit from the cytosol to the nucleus provide an additional argument for the involvement of this transcription factor in the induction of GST and NQO1.

On the other hand, several lines of evidence suggest the linkage between the aryl hydrocarbon receptor and Nrf2 batteries, achieved probably by multiple mechanisms, including $N r f 2$ as a target gene of the aryl hydrocarbon receptor $^{(23)}$.

Among the GST isozymes, treatment with cabbage juices affected the most the hepatic GST $\mu$ and to a lesser extent 


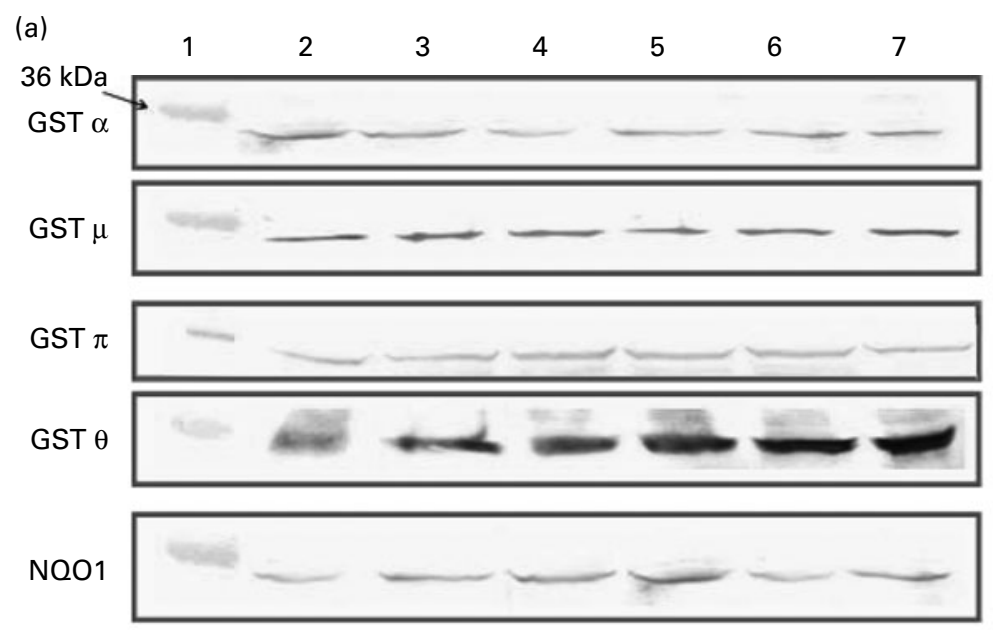

(b)

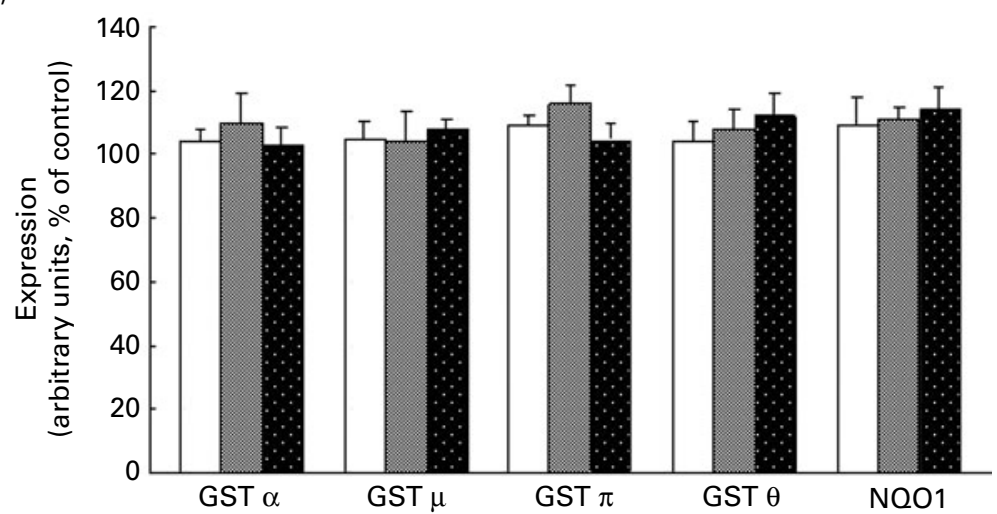

Fig. 6. Expression of glutathione $S$-transferase (GST) isozymes and $\mathrm{NAD}(\mathrm{P}) \mathrm{H}$ :quinone oxidoreductase 1 (NQO1) in rat kidney treated with phenethyl isothiocyanate (PEITC). (a) A representative immunoblot from two independent experiments. (b) Data presented as percentage of control groups (means with their standard errors) from two separate experiments run in triplicate. Lane 1, molecular weight marker or standard for GST $\alpha$; lane 2, control (4d); lane 3, PEITC (4 d, $\square$ ); lane 4, control (10 d); lane 5, PEITC (10 d, 圆); lane 6, control (30 d); lane 7, PEITC (30 d, 這).

GST $\alpha$. The increased level of these isozymes might be beneficial in protecting against reactive oxygen species and products of lipid peroxidation, such as 4-hydroxynonenal $^{(24)}$. Moreover, GST $\mu$ has shown a high activity towards most polycyclic aromatic hydrocarbon epoxides ${ }^{(25)}$. This activity may be particularly interesting, since it was coordinated with the elevated expression and activity of NQO1. This enzyme is a cytosolic flavoprotein that catalyses metabolic detoxification of quinones, including benzo $[a]$ pyrene quinones, by converting them into hydroquinones via a single-step two-electron reduction, thus avoiding the formation of deleterious reactive semiquinones $^{(6)}$.

The results of recent studies with $\mathrm{NQO1}^{-/-}$and $\mathrm{NQO}_{2}{ }^{-/}$mice have suggested that NQO1, together with $\mathrm{NQO} 2$, protects against polycyclic aromatic hydrocarboninduced skin carcinogenesis ${ }^{(26)}$. One possible mechanism of this protection, which might be applicable also to other tissues, is the fact that NQO interact and protect p53 protein, the key regulator of the control of cell growth, from $20 \mathrm{~S}$ proteasome degradation. This leads to stability and transient activation of p53 and cellular protection through the cell cycle arrest, senescence or apoptosis $^{(27)}$.

In contrast to the liver, cabbage juices did not affect the renal GST and NQO1 expressions, except GST $\theta$. The low level of GST $\theta$ in the kidney demonstrates the poor constitutive expression of GST $\theta$ class in this tissue. Moreover, the alterations in the GST $\theta$ protein level did not result in changes in GST enzyme activity towards the classical substrate 1-chloro-2,4-dinitrobenzene, used in the present study, since 1-chloro-2,4-dinitrobenzene is not a substrate for GST $\theta^{(28)}$.

GST $\theta$ may act as an activator of halogenated compounds. Moreover, there was an increased risk of kidney and liver tumours in human subjects with the GSTT-1-positive genotype, following exposure to halogenated solvents. Thus, the GSTT-1 genotype is supposed to confer decreased or increased risk of cancer in relation to the source of exposure. The level of GSTT-1 subunit within tissues is an important determinant of susceptibility to the carcinogenic effects of dihaloalkanes. Cabbage juice, by reducing the GST $\theta$, may protect against nephrocarcinogenicity of chlorinated hydrocarbons, especially taking 

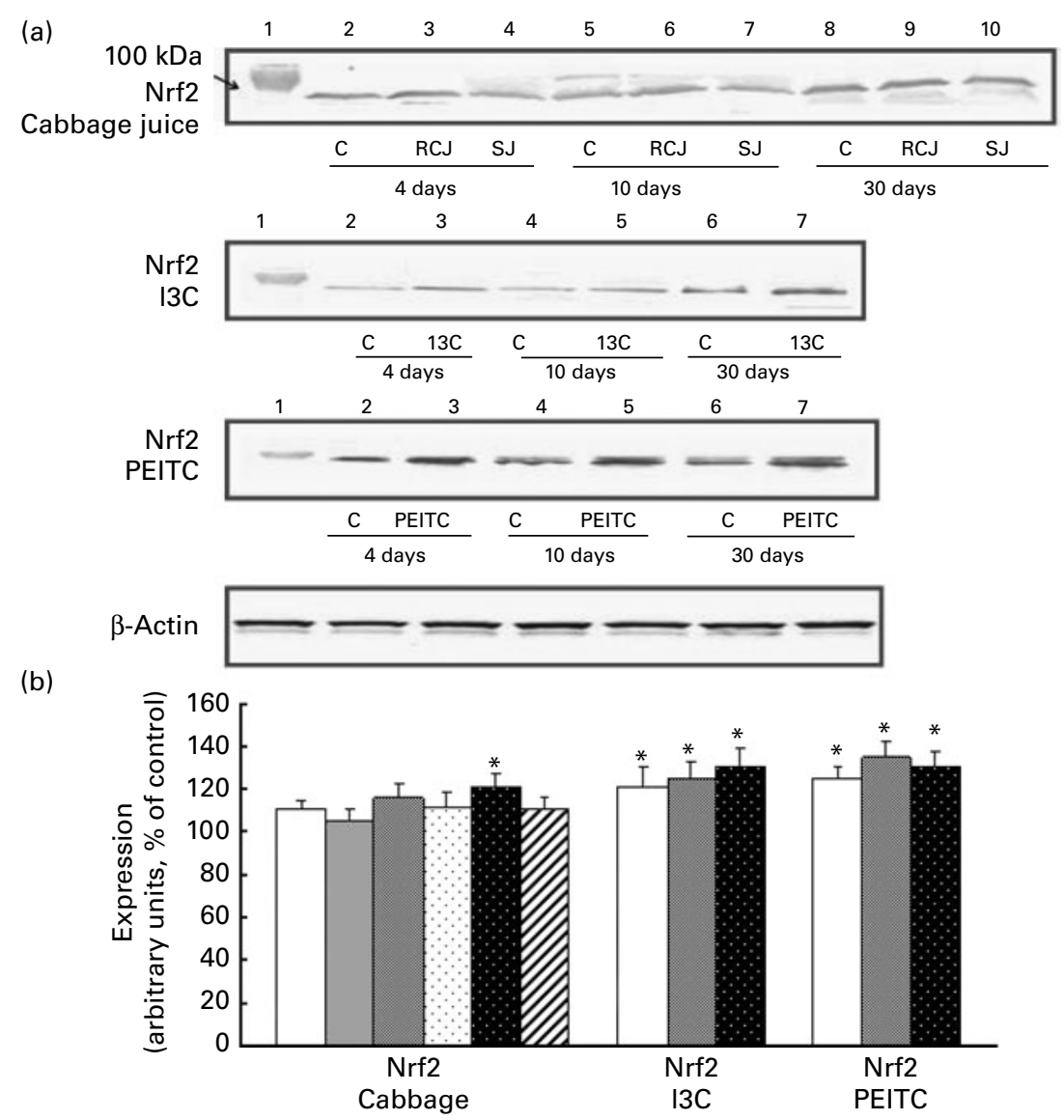

Fig. 7. Expression of NF-E2-related transcription factor (Nrf2) in nuclear fractions from the rat liver treated with cabbage juices, indole-3-carbinol (I3C) and phenethyl isothiocyanate (PEITC). (a) A representative immunoblot from two independent experiments. (b) Data presented as percentage of control groups (means with their standard errors) from two separate experiments run in triplicate. * Mean values were significantly different from the control group $(P<0.05)$. Lane 1, molecular weight marker; lane 2, control (4 d); lane 3, raw cabbage juice (RCJ), I3C and PEITC (4 d, $\square$ ); lane 4, sauerkraut juice (SJ; 4 d, $\square$ ); lane 5, con-

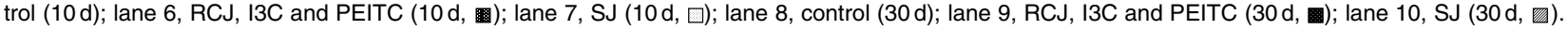

into account that the initial GST-dependent bioactivation step of nephrocarcinogenesis by chlorinated hydrocarbons may take place in the kidney itself, and the liver is not the main site of their initial conjugation ${ }^{(29)}$. This indicates that extrahepatic induction of detoxifying enzymes requires higher concentrations of active compounds than those occurring in cabbage juices.

Thus, the results of the present and earlier studies ${ }^{(30)}$ indicate that induction of the key detoxifying enzymes by cabbage juices, particularly sauerkraut, may be responsible for their chemopreventive activity demonstrated by epidemiological studies and in animal models. The final effects, however, might be organ or tissue dependent.

\section{Acknowledgements}

The present study was supported by the Ministry of Science and Higher Education of Poland, grant 2 PO6T 085 26. The authors declare no conflict of interest. V. K.-K. helped in planning and performing the animal experiments, Western blot analysis and writing the first draft of the manuscript; H. S. helped in planning and performing the animal experiments, enzymes' activity assay and writing the first draft of the manuscript; A. B. helped in preparing and analysing of cabbage juices; W. B.-D. helped in planning the experiments and writing the manuscript.

\section{References}

1. Zhang Y, Munday REX, Jobson HE, et al. (2006) Induction of GST and NQO1 in cultured bladder cells and the urinary bladders of rats by and extract of broccoli (Brassica oleracea var. italica) sprouts. J Agric Food Chem 54, 9370-9376.

2. Higdon JV, Delage B, Williams DE, et al. (2007) Cruciferous vegetables and human cancer risk: epidemiologic evidence and mechanistic basis. Pharmacol Res 55, 224-236.

3. Ciska E \& Pathak DR (2004) Glucosinolate derivatives in stored fermented cabbage. I Agric Food Chem 52, $7938-7943$.

4. Villaluenga-Martinez C, Penas E, Frias J, et al. (2009) Influence of fermentation conditions on glucosinolates, ascorbigen, and ascorbic acid content in white cabbage (Brassica oleracea var. capitata cv. Taler) cultivated in different seasons. J Food Sci 74, 62-67.

5. Wagner AE \& Rimbach G (2009) Ascorbigen: chemistry, occurrence, and biologic properties. Clin Dermatol 27, $217-224$ 
6. Keum Y-S, Han Y-H, Liew C, et al. (2006) Induction of heme oxygenase-1 (HO-1) and NAD[P]H: quinone oxidoreductase 1 (NQO1) by a phenolic antioxidant, butylated hydroxyanisole (BHA) and its metabolite, tert-butylhydroquinone (tBHQ) in primary-cultured human and rat hepatocytes. Pharm Res 23, 2586-2594.

7. Williamson G, DuPont MS, Wanigatunga S, et al. (1995) Induction of glutathione $S$-transferase activity in hepG2 cells by extracts from fruits and vegetables. Food Chem $\mathbf{6 0}$, $157-160$.

8. Bogaards JJP, Verhagen H, Willens ML, et al. (1994) Consumption of Brussels sprouts results in elevated $\alpha$-class glutathione $S$-transferase levels in human blood plasma. Carcinogenesis 15, 1073-1075.

9. Zhang X \& Malejka-Giganti D (2003) Effects of treatment of rats with indole-3-carbinol on apoptois in the mammary gland and mammary adenocarcinomas. Anticancer Res $\mathbf{2 3}$, 2473-2480.

10. Adam-Rodwell G, Morse MA \& Stoner GD (1993) The effects of phenethyl isothiocyanate on benzo[ $a]$ pyrene-induced tumors and DNA adducts in A/J mouse jung. Cancer Lett 71, 35-42.

11. Kusznierewicz B, Śmiechowska A, Bartoszek A, et al. (2008) The effect of heating and fermenting on antioxidant properties of white cabbage. Food Chem 108, 853-861.

12. Krajka-Kuźniak V, Szaefer H \& Baer-Dubowska W (2004) Modulation of 3-methylcholanthrene-induced rat hepatic and renal cytochrome P450 and phase II enzymes by plant phenols: protocatechuic and tannic acids. Toxicol Lett 152, $117-126$.

13. Krajka-Kuźniak V, Kaczmarek J \& Baer-Dubowska W (2008) Effect of naturally occurring phenolic acids on the expression of glutathione $S$-transferase isozymes in the rat. Food Chem Toxicol 46, 1097-1102.

14. Nijhoff WA, Groen GM \& Peters WHM (1993) Induction of rat hepatic and intestinal glutathione,I-transferases and glutathione by dietary naturally occurring anticarcinogens. Inter J Oncol 3, 1131-1139.

15. Morimitsu Y, Nakagawa Y, Hayashi K, et al. (2002) A sulforaphane analogue that potently activates the Nrf2-dependent detoxification pathway. J Biol Chem 277, 3456-3463.

16. Nelson NJ (2006) Migrant studies aid the search for factors linked to breast cancer risk. J Natl Cancer Inst 98, 436-438.

17. Kristal AR \& Lampe JW (2002) Brassica vegetables and prostate cancer risk: a review of the epidemiological evidence. Nutr Cancer 42, 1-9.

18. Larsson SC, Hakansson N, Naslund I, et al. (2006) Fruit and vegetable consumption in relation to pancreatic cancer: a prospective study. Cancer Epidemiol Biomarkers Prev 15, 301-305.

19. Stephensen PU, Bonnesen C, Bjeldanes LF, et al. (1999) Modulation of cytochrome P4501A1 activity by ascorbigen in murine hepatoma cells. Biochem Pharmacol 58, 1145-1153.

20. Kravchenko LV, Avren'eva LI, Guseva GV, et al. (2001) Effect of nutritional indoles on activity of xenobiotic metabolism enzymes and T-2 toxicity in rats. Bull Exp Biol Med 131, $544-547$.

21. Kong AN, Owuor E, Yu R, et al. (2001) Induction of xenobiotic enzymes by the MAP kinase pathway and the antioxidant or electrophile response element (ARE/EpRE). Drug Met Rev 33, 255-271.

22. Talalay P \& Fahey JW (2001) Phytochemicals from cruciferous plant protect against cancer by modulating carcinogen metabolism. J Nutr 131, S3027-S3033.

23. Köhle C \& Bock KW (2006) Activation of coupled Ah receptor and Nrf2 gene batteries by dietary phytochemicals in relation to chemoprevention. Biochem Pharmacol 72, 795-805.

24. Yang Y, Sharma R, Sharma A, et al. (2003) Lipid peroxidation and cell cycle signaling: 4-hydroxynonenal, a key molecule in stress mediated signaling. Acta Biochim Pol 50, 319-333.

25. Tang SC, Sheu GT, Wong RH, et al. (2010) Expression of glutathione $S$-transferase M2 in stage I/II non-small cell lung cancer and alleviation of DNA damage exposure to benzo[a]pyrene. Toxicol Lett 192, 316-323.

26. Shen J, Barrios J \& Jaiswal AK (2010) Inactivation of the quinone oxidoreductases NQO1 and NQO2 strongly elevates the incidence and multiplicity of chemically induced skin tumors. Cancer Res 70, 1006-1013.

27. Gong X, Kole L, Iskander K, et al. (2007) NRH: quinone oxidoreductase 2 and $\mathrm{NAD}(\mathrm{P}) \mathrm{H}$ :quinone oxidoreductase 1 protect tumor suppressor $\mathrm{p} 53$ against 20 s proteasomal degradation leading to stabilization and activation of $\mathrm{p} 53$. Cancer Res 67, 5380-5388.

28. van Lieshout EM, Bedaf MM, Pieter M, et al. (1998) Effects of dietary anticarcinogens on rat gastrointestinal glutathione S-transferase theta 1-1 levels. Carcinogenesis 19, 2055-2057.

29. Sherratt PJ, Manson MM, Thomson AM, et al. (1998) Increased bioactivation of dihaloalkanes in rat liver due to induction of class theta glutathione $S$-transferase T1-1. Biochem J 335, 619-630.

30. Baer-Dubowska W, Szaefer H \& Krajka-Kuźniak V (2008) The effect of cabbage juice and its components on the expression and activity of phase 1 and 2 enzymes in rats. Eur J Cancer Suppl 6, 44. 